\title{
The Möbius strip of market spatiality: mobilizing transdisciplinary dialogues between CCT and the marketing mainstream
}

\author{
Jack Coffin ${ }^{1} \cdot$ Andreas Chatzidakis $^{2}$
}

Received: 17 February 2020 / Accepted: 25 November 2020 / Published online: 25 January 2021

(c) The Author(s) 2021

\begin{abstract}
This paper develops the Möbius strip as an 'ordering theory' (Sandberg and Alvesson, 2020) that brings CCT studies into dialogue with mainstream marketing approaches. The aim is to work toward a transdisciplinary understanding of market spatiality, a topic that has become increasingly important for theorists and practitioners (Warnaby and Medway, 2013; Castilhos et al., 2016; Chatzidakis et al., 2018). Building on psychosocial interpretations of the Möbius strip as a 'tactical' way of thinking, a range of insights and ideas are organized along a single strip of theorization. This paper maps a continuous plane of logic between the concepts of space, place, emplacement, spatiality, implacement, and displacement. The potential applications of the Möbius strip are then demonstrated by showing how the transdisciplinary topic of 'atmosphere' can be theorized from multiple perspectives. The paper concludes by exploring how the Möbius strip might also be employed in other areas of marketing theory and practice, potentially generating further transdisciplinary conversations between CCT and the marketing mainstream.
\end{abstract}

Keywords CCT $\cdot$ Marketing $\cdot$ Möbius strip $\cdot$ Space $\cdot$ Place $\cdot$ Spatiality $\cdot$ Emplacement $\cdot$ Implacement $\cdot$ Displacement $\cdot$ Atmosphere $\cdot$ Atmospherics $\cdot$ Servicescapes $\cdot$ NRT $\cdot$ Customer journey

\section{Introduction}

"Increasing emphasis is being put on the fact that all social processes take place somewhere, and that where this somewhere is makes a major difference."

(Hien et al., 2008, p.1268).

When Arnould and Thompson (2005, p.868) first introduced the "academic brand" of Consumer Culture Theory (CCT) they described it as "a flurry of research addressing the sociocultural, experiential, symbolic, and ideological aspects of consumption", contrasting this with the "microeconomic theory, cognitive psychology, experimental design, and quantitative analytical methods" (p.869) found elsewhere in the marketing discipline. This branding

Jack Coffin

jack.coffin@manchester.ac.uk

1 Department of Materials, University of Manchester, Manchester, UK

2 School of Business and Management, Royal Holloway, University of London, London, UK exercise has been very successful in legitimating alternative approaches to studying markets and consumption (Arnould and Thompson, 2015, 2018), but it runs the risk of creating an epistemic enclave. A simplistic reading of Arnould and Thompson (2005) would suggest that CCT exists on its own paradigmatic plane with insights, ideas, and interests that are incommensurable with those of the marketing mainstream. However, CCT is best defined as a heteroglossia (Thompson et al., 2013), an approach to theory and practice that is openended, open-to-change, and comprised of open-minded academics. Adopting a more open definition of CCT helps to discern ways in which this body of knowledge can enter into transdisciplinary conversations and collaborations with the marketing mainstream (Arnould et al., 2019). One area that would certainly benefit from scholarly cross-pollination is market spatiality, a term which encompasses a range of research addressing the relationships between geographical processes and marketing practices (Castilhos et al., 2016).

Management scholars of various stripes have been interested in the broad topic area of market spatiality for over five decades (Giovanardi and Lucarelli, 2018), but only recently have these studies reached a critical mass since described as a 'spatial turn' for marketing (Chatzidakis et al., 2018). 
Scholars associated with the CCT tradition have contributed greatly to contemporary understandings of market spatiality (see Castilhos et al., 2016), but so too have scholars drawing on other disciplines, like psychology or economics. This is particularly clear in place marketing. Once an area of inquiry led by practitioners interested in marketing destinations, cities and regions, it now attracts academics from a plethora of philosophical perspectives (Warnaby and Medway, 2013; Giovanardi et al., 2019). Unfortunately, place marketing stands as somewhat of an exception to the rule of market spatiality, where the transfer of ideas between CCT scholarship and mainstream marketing research is relatively rare.

Take an everyday notion like atmosphere. Manageriallyoriented research tends to gravitate toward Kotler's (1973) concept of atmospherics, which has since split into subcategories like multisensory atmospherics (Spencer et al., 2014) and outdoor atmospherics (Bloch and Kamran-Disfani, 2018). Many marketing scholars are influenced by environmental psychology, conceptualizing atmospheres as bundles of ambient sensory stimuli that can exert an often subliminal influence on in situ consumer subjects (Turley and Milliman, 2000; Turley and Chembat, 2002). CCT scholars often employ Thrift's (2008) Non-Representational Theory (NRT) to address this theme of subliminality, as well as conceptualizing how atmospheres can become mobile phenomena, able to move between bodies and thus between sites (Hill et al., 2014; Hill, 2016). In addition, the CCT tradition addresses how atmospheres are also local manifestations of cultural themes like utopia (Maclaran and Brown, 2005) or home (Bradford and Sherry, 2015). Although more recent contributions seek to draw together ideas from a range of theoretical traditions (e.g. Steadman et al., 2020), the study of atmospheres remains characterized by a series of welldeveloped but rather discrete areas of knowledge.

A similar statement could be made for many other market-spatial phenomena, such as customer journeys through market spatiality (Hill et al., 2014; Coffin, 2019; Thomas et al., 2020; Grewal and Roggeveen, 2020), consumer experiences in and of market spatiality (e.g. Verhoef et al., 2009; Chatzidakis et al., 2018; Roggeveen et al., 2020), or individual and collective emotional responses to market spatiality (e.g. Warnaby and Medway, 2013; Debenedetti et al., 2014; Rosenbaum et al., 2017). The marketing literature addressing these topics can certainly be described as multi-disciplinary, but rarely are the terms cross-disciplinary, interdisciplinary, or transdisciplinary as applicable. In response, this conceptual paper seeks to propose an 'ordering theory' (Sandberg and Alvesson, 2020) that helps to reorganize the existing body of research on market spatiality and, in doing so, highlights hitherto unseen opportunities for future research that cuts across disciplinary divides. The mental model for this theoretical reordering is the Möbius strip, a shape that twists to allow multiple positions to coexist on the same continuous plane. Similarly, this paper argues that the ideas and insights of CCT scholars can be located alongside those of mainstream marketing academics and practitioners - different but not necessarily discrete.

The remainder of this paper is structured as follows: the next section details the notion of the Möbius strip as an ordering theorization in general terms before proposing the Möbius strip of market spatiality as a more specific formulation; the subsequent sections move along the Möbius strip of market spatiality by addressing 6 common concepts (space, place, emplacement, spatiality, implacement, and displacement) that can be applied to studies from the CCT tradition and the marketing mainstream; the paper then returns to the topic of 'atmosphere' to provide a more concrete example of how the Möbius strip of market spatiality might be applied by future researchers; finally, the conclusion considers the broader issue of CCT's relationship with the marketing mainstream, proposing that other Möbius strips might be mobilized in order to facilitate transdisciplinary conversations, insights, and theorizations.

\section{The Möbius strip as an ordering theorization}

A Möbius strip is created by taking a long thin piece of paper and twisting it 180 degrees in the middle before attaching both ends, producing a multi-directional geometry from a single plane (Fig. 1). Looking at the Möbius strip from afar produces the optical illusion of folds and cuts, yet an insect moving along its surface would experience an uninterrupted plane of movement. As Frosh and Baraitser (2008, p.349) explain, "underside and topside, inside and out, flow together as one, and the choice of how to see them can be purely tactical, just like the decision as to whether to look at the subject from a "social" or a "psychological" perspective". Analogously, one may choose to conceptualize market spatiality as a single plane of transdisciplinary theorization. Although certain ideas or insights may be more closely associated with one perspective (e.g. CCT), the Möbius strip points to the benefits of thinking 'tactically', of emphasizing connections and continuities rather than a priori disciplinary differences.

The Möbius strip is not unique to any particular scholar, subject, or sub-discipline. More often than not, it is used fleetingly as a metaphor amongst many other arguments. For example, Grosz (1994, p.209) uses the geometry as a feminist figure of speech, denoting the inexorable entwinement of the gendered mind and body. In their study of tailgating vestavals, Bradford and Sherry (2015, p.130) present their findings as a Möbius strip in order to "emphasize not just the simultaneity of stages, but also the constant sharing of energy". Their usage points to the 
Fig. 1 A Möbius strip

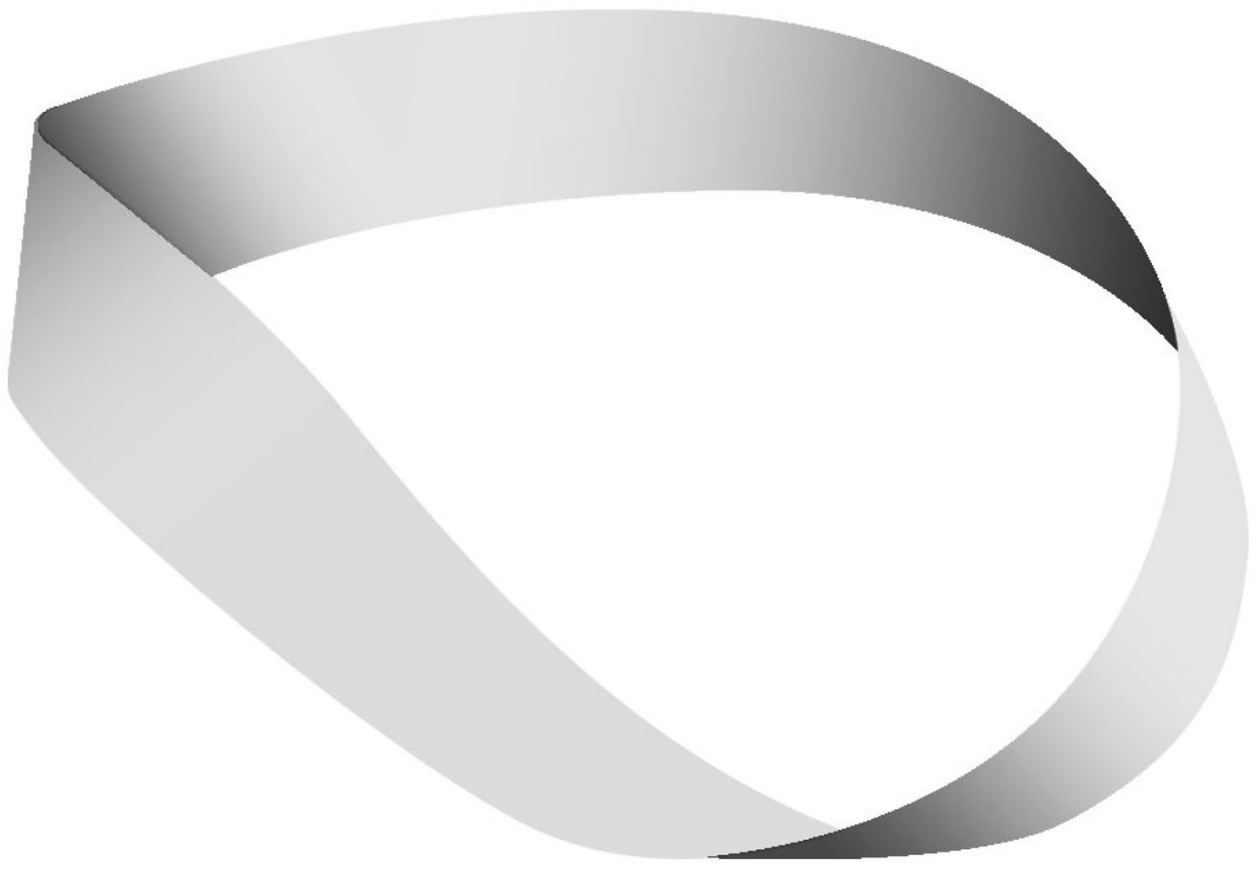

heuristic power of the Möbius strip, but primarily in relation to a specific type of market spatiality (the vestaval). Building on their example, this paper attempts to deploy the Möbius strip more broadly as an 'ordering theory' (Sandberg and Alvesson, 2020), integrating different types of market spatiality into a single theoretical framework or 'plane'. This use of the Möbius strip is inspired by the psychosocial studies of Frosh (2014, p.161), who uses this to theorize "the ways in which psychic and social processes demand to be understood as always implicated in each other, as mutually constitutive, co-produced, or abstracted levels of a single dialectical process."

Psychosocial studies emerged in the mid-1980s as staff and students at British universities expressed an interest in courses that addressed both individual and larger-scale social experiences (Frosh, 2003). As the unhyphenated appellation suggests, studies in this area seek to dissolve the disciplinary distinctions between 'psychological' and 'sociological' thinking in order to appreciate the human condition as inherently psychosocial (Frosh and Baraitser, 2008; Woodward, 2015). Psychosocial scholars sought to avoid the pitfalls of sociological and psychological reductivism (Frosh and Baraister, 2008), advocating instead methodological and theoretical pluralism (Frosh, 2003, 2010; Woodward, 2015). To summarise, psychosocial studies can be thought of "as an interdisciplinary field in search of transdisciplinary objects of knowledge" (Frosh, 2014, p.161). Like other areas of theoretical development it provides an "integrated understanding of the phenomena of interest" (Vargo and Koskela-Huotari, 2020, p.2), but one that seeks to integrate ideas and insights from origins that are ostensibly opposed.
Parallels can be drawn to the present attempt to theorize market spatiality as a combination of CCT and mainstream marketing approaches. Although CCT is already theoretically and methodologically pluralistic (Thompson et al., 2013), there have been calls for more sustained engagement with mainstream theories and managerial practice (Arnould et al., 2019). Building on previous reviews of the market spatiality literature (Castilhos et al., 2016; Lucarelli and Giovanardi, 2019), the novel contribution of a Möbius strip is to order the literature in ways that encourage transdisciplinary conversations and collaborations. The Möbius strip of market spatiality connects space, place, emplacement, spatiality, implacement, and displacement together along one continuous plane. The following six sections move along this plane, oscillating freely between CCT studies and those from the marketing mainstream. Although differences can still be discerned these become less distinct as opportunities for cross-pollination become more prominent.

\section{From space to place}

Previous orderings of market spatiality have been oriented around the conceptual contradistinction between 'space' and 'place' (Chatzidakis et al., 2018; Giovanardi and Lucarelli, 2018). As both terms are used in everyday discourse, it is perhaps unsurprising that there is some disagreement about how they should be defined and delineated (Agnew, 2011; Low, 2016). In contrast to other areas of social theory, the marketing discipline deploys a relatively consistent distinction. This conceptual consensus is deftly distilled by 
Visconti et al. (2010, p.512), who write that "the notion of space traditionally refers to something anonymous, whereas place distinctively accounts for the meaningful experience of a given site". Put simply, meaning marks the boundary between space and place for most marketing theorists. This is why it makes sense to speak of 'place marketing', which denotes the commercial management of toponyms, scenic imagery, and other geographical-semiotic assets (Warnaby and Medway, 2013), but not 'space marketing', which would denote the management of unknown or undefined geographies.

CCT scholars have emphasized how places emerge and evolve through the interactions of various spatial stakeholders (Kozinets et al., 2004; Maclaran and Brown, 2005; Warnaby and Medway, 2013). Therefore, placemaking is not simply the benign creation and manipulation of meanings; CCT research has shown that these attempts to make-place must generally be understood as 'territorial' in the sense of claiming an area then seeking to control how it is interpreted and appropriated (Cheetham et al., 2018). Although few places become so tightly controlled as to be territories in the strictest sense of the term (Castilhos et al., 2016), territorial tendencies can be discerned across a range of marketing contexts. Examples in the CCT literature include consumers rearranging coffee shops to fit their needs (Venkatraman and Nelson 2009), citizens creating anti-commercial enclaves (Chatzidakis et al., 2012), and locals co-producing the temporal rhythms of urban parks (McEachern et al., 2012). Territorial tendencies can also be identified in the mainstream marketing literature, from managerial attempts to intervene in the surroundings of retail stores (Bloch and Kamran-Disfani, 2018), through the internal organization of stores on the basis of differing social groups and activities (Baker, 1987; Baker et al., 1992; Venkatraman and Nelson, 2009), to designs that create territories for therapeutic recuperation (Rosenbaum, 2009) or "artistic" expression (Vukadin et al., 2019) at the expense of other potential uses. These can be read as illustrations of territorial tendencies because they are characterized by the zero-sum game of place-making actors competing over the limited resource of space.

In addition to meaning-making, the term territorialization highlights a second distinction between space and place. The former is often presented as pre-territorial, as open-ended and unidentified, while the latter follows from territorial processes, with a simple definition of place being a demarcated and identified area of space (Cresswell, 2004). This is implied above when Visconti et al. (2010, p.512-3) write of place as "a given site", and elaborated further when they add that "inchoate space (such as "outer space," "wilderness," and "wasteland") is rendered tractable by dwelling practices (Seamon, 1993) that can convert it into place." If space is meaningless but also open, then place-making is partly about setting physical and psychical perimeters to separate significant areas from the anonymous mass (Cresswell, 1992). Boundaries have featured in many CCT studies of place, such as Maclaran and Brown's (2005) vivid description of the Powerscourt festival mall in Dublin. This place created an 'otherworldly' and 'utopian' experience though a stark physical contrast between its interior, as disorderly and nostalgic, and its exterior, the orderly and generic store environments of the surrounding streets. A more extreme case is the Athenian district of Exarcheia, which developed an identity as an 'other place' for social experimentation, or heterotopia (Foucault, 1967), because of the contrast between the neighborhood's physical environment and socioeconomic practices from the rest of Athens (Chatzidakis et al., 2012). Marketing studies outside the CCT tradition also demonstrate the importance of boundaries, albeit often in a more subtle way, for instance by exploring how consumers rearrange furniture and other features to create smaller personal places within the shared spaces of coffee shops (Venkatraman and Nelson, 2008).

As suggested by the examples above, mainstream marketing scholars share much in common with their CCT counterparts when it comes to how they conceptualize space and place. However, it is worth noting that CCT scholars tend to be more attentive to the processes by which space becomes place, whereas mainstream marketing tends to be more focused on managing market places as pre-existing entities. Outside of the CCT tradition, many marketing studies tacitly adopt the common-sense theorization of space as the static Euclidian container of reality within which entities (e.g. consumers and products) and events (e.g. economic exchanges) can be located using Cartesian coordinates. Meanwhile place denotes smaller containers within this universal space that can be identified, branded, and managed. This logic can be found inscribed in almost any marketing textbook, with 'place' presented eponymously as one of the ' 4 Ps' of the marketing mix (Chatzidakis et al., 2018). From this perspective, managers are advised to seek out "settings that facilitate utilitarian exchanges between buyers and sellers, in which both parties exchange money, goods, or services" (Rosenbaum et al., 2017 , p.281). However, the place-making processes by which these settings emerge and evolve are rarely addressed in mainstream theory and practice. This also applies to more recent notions of "outdoor atmospherics" (Bloch and Kamran-Disfani, 2018) and "out of store retail journey touchpoints" (Roggeveen et al., 2020), although recent moves to conceptualise retail atmospherics within broader social-political-cultural surroundings (e.g. Grewal and Roggeveen, 2020) suggest opportunities for collaboration between CCT scholars and marketing mainstream researchers.

CCT insights into place-making can also contribute to mainstream marketing practice. Managers and other market actors make places through practices as varied as brand 
dictated themes (Foster and McLelland, 2015), the insertion of artwork (Vukadin et al., 2019), and the inclusion of indoor plants (Tifferet and Vilnai-Yavetz, 2017). The CCT insight is that these managerial practices are always co-operating and/or competing with the place-makings of consumers. The success of shopping malls, arcades, and other retail environments are evidence that managers recognize the power of placemaking (Parsons et al., 2016), but their practical knowledge could be augmented by further analytic and conceptual insights into the place-making processes of consumers. Here transdisciplinary collaborations between CCT scholars and mainstream marketing researchers may be particularly beneficial. For instance, Medway and Warnaby (2017, p.155) point to crowdsourced 'smell maps' as "a numeric as well as a narrative data stream" that documents how cities are experienced as a patchwork of odorous territories: from a CCT perspective, "the main value of such data is in the rich sensory discourses", but it is important to add that "numeric data feeds should provide a reassuring data stream for those of a more positivist persuasion." Smell maps are a spontaneously-generated data set around which marketing scholars of various stripes can study olfactory place-making in real-time, providing powerful insights for store managers, urban planners, and other meaning-making territorial actors.

\section{Places or emplacement?}

Many CCT scholars have been heavily influenced by phenomenological geographers, for whom "the essence of human existence... is necessarily and importantly in"place"" (Cresswell, 2004, p.349). This is a subtle yet significant shift in conceptualization; phenomenological geography treats people and places as intimately and inexorably entwined, and this co-constitutive relationship broadens the unit of analysis beyond "the meaningful experience of a given site" (Visconti et al., 2010, p.512), to the meanings and experiences generated by moving between and within sites (Bradford and Sherry, 2015). Put differently, phenomenological approaches do not treat places as discrete sites of activity, but rather see all activities as 'emplaced' (Bradford and Sherry, 2018). When thinking in terms of a Möbius strip this can be described as a 'twist' in thinking: place and emplacement are conceptually similar yet they point to a different series of research questions and insights. While the concept of place stimulated studies of specific sites, emplacement acknowledges that "all consumption is in space and place" (Chatzidakis et al., 2018, p.152). This means that rather than treat 'place consumption' as a sub-category of consumption practices more broadly, CCT scholars have increasingly sought to understand how all consumption is emplaced in more-or-less obvious ways.
Consumption communities illustrate how market emplacements operate in everyday consumption practices. Thomas et al. (2013) note how contemporary communities are usually organized around a brand, product, or activity, rather than the communities of place found in pre-industrial societies. However, although this means that the identities of many communities are 'placeless' (Muñiz and O'Guinn, 2001), community practices still need suitable locations in which to 'take place'. The identities of communities and other collectives can be created and sustained by the Internet and other communication technologies (Muñiz and O'Guinn, 2001; Cayla and Eckhardt, 2008; Ardvisson and Caliandro, 2016), but a stronger sense of identity and loyalty emerges when these abstract affiliations are also substantiated by face-to-face encounters (Hoelscher and Chatzidakis, 2020). This stresses the persistent importance of physical emplacements, even if these are only ephemeral, as a means through which brand communities and other consumer groups gather together to share their passions (Bradford and Sherry, 2018).

Parallels can be drawn with the term 'social' that is used within the mainstream marketing literature, usually to contrast with the sensorial dimensions of stores and other environments. Baker (1987) identifies social factors as an important determinant of the service environments, giving examples like the presence of other consumers or service personnel (see also Baker et al., 1992). Similarly, a key distinction between Bitner's (1992) servicescape model and Kotler's (1973) atmospherics is the additional emphasis on social interactions, both between consumers and at the consumer/employee interface. These can be thought of as emplacements insofar as social groups are associated with a particular store environment, sometimes in ways that managers and designers did not intend (Aubert-Gamet and Cova, 1999). Servicescape researchers have empirically demonstrated how social identities can affect consumers' experiences of service environments (Rosenbaum, 2005; Rosenbaum and Walsh, 2012), but generally these social identities are presented as pre-existing associations between people and places. In contrast, CCT studies tend to present emplacement as an ongoing process (Bradford and Sherry, 2018), helping to explain how consumers engage with social identities at a local level but also how these local engagements can alter social identities more broadly (Thompson and Üstüner, 2015).

Emplacements are successful when market actors identify places with physical affordances and symbolic associations that are suitable to their objectives. Thomas et al. (2013, p.1025) describe this as the problem of structural alignment, whereby actors seek to "alleviate tensions associated with diverse members occupying the same physical and cultural space." Similar tensions are noted by Kozinets et al. (2004), who explore how the consumers, employees, and managers 
of a flagship store co-exist in close proximity but with differing interests and objectives. These actors engage in games of inter-agency, following but also breaking the implicit rules of this enclosed commercial site. The lesson of this study is that individuals or groups seeking to emplace their activities must learn 'how to play the game', with each site having its own rules. Skandalis et al. (2018) explored similar dynamics in their multi-sited ethnography of how places contribute to the formation of taste in relation to music consumption. Comparing classical music venues with indie festivals, their study demonstrates how music consumers emplace themselves by discerning the implicit rules of the musical places and acting appropriately (see also Skandalis et al., 2017; Skandalis et al., 2020). To provide another example from the CCT literature, Hoeslcher and Chatzidakis (2020) note how digital technologies now allow ethical consumers to escape physical restraints and expand their activities, but also stress how face-to-face activities continue to add value and vitality to their communities, necessitating regular emplacements of ethical consumption. Taken collectively, these studies suggest that emplacement is still an important skill for contemporary consumers, and that studying how consumers learn to emplace their consumption in different sites may be a fruitful avenue for future transdisciplinary research.

Before discussing how mainstream marketers may collaborate with CCT researchers on the topic of emplacement, it is worth noting that the need for structural alignment points to the possibility of misalignments-cases where actors' emplacements do not 'fit' with the ambience of a particular place. This possibility was explored by Allen (2002), who studied how the experience of feeling 'in-place' or 'out-ofplace' was a considerable factor in prospective students' choice of college. More successful emplacements emerged when the atmosphere of the campus aligned with the individual's habitual sense of self, which Allen (2002) argues is a product of their socioeconomic background. A number of other studies have shown how identity positionings along the axes of race, age, disability and gender can significantly impact how a place is perceived and, subsequently, where consumers choose to emplace their consumption (Sherry et al., 2004; Goulding and Saren, 2009; Thompson and Üstünter, 2015). CCT studies are replete with examples of emplacement being entwined with a consumer's sense of self, but an especially detailed illustration is Kates's (2002) ethnographic study of gay men in North America. His data describe consumers who feel 'out-of-place' in everyday environments due to their sexual orientation, even when this is not disclosed to, or recognized by, others. As such, these men chose to emplace the vast majority of their consumption in 'gay ghettos' in order to avoid discrimination, stigma, and even violence elsewhere. However, the emplacement patterns of such consumers have altered as social attitudes to sexuality have changed (Coffin et al., 2019), highlighting the importance of process theorizing for CCT researchers (Giesler and Thompson, 2016).

From a more mainstream perspective, Rosenbaum (2005) makes similar remarks about gay male consumers and draws parallels with Jewish consumers, conceptualizing the experience of both as a 'symbolic servicescape'. While Bitner's (1992) concept of servicescapes combined the sensory stimuli of environmental psychology with the social factors raised by service marketers, Rosenbaum's (2005) work demonstrates how emplacements can go awry if symbolic considerations are not considered as well (see also Rosenbaum and Massiah, 2011). Moving beyond the servicescape concept, such studies suggest moments where emplacement may not work seamlessly, offering brand managers, place designers, and other spatial stakeholders an opportunity to adapt their environments. Thomas et al. (2020) recently explored the various roles that retailers can play in collective consumer journeys, such as those made by families or friends through a service environment, a study that can be reinterpreted through the lens of emplacement to consider how managers can empower consumers to have more fulfilling engagements with their service environments. It is worth noting that such emplacements may go far beyond an enjoyable service experience: consider Rosenbaum's (2009) argument that servicescapes can be 'restorative' for those with Attention Deficit Hyperactivity Disorder (ADHD). As such, discussions should also include policy-makers and other non-commercial stakeholders insofar as sensory, social, and symbolic aspects can empower consumers to emplace themselves and others in beneficial ways.

\section{Space or spatiality?}

After twisting from places to emplacements the Möbius strip seems to move back toward the concept of space once again. However, because of this twist the approach is now on the opposite side of the strip, toward spatiality rather than space. As noted earlier, space is an "anonymous" and open-ended concept (Visconti et al., 2010, p.512), often assumed to be an inert container (Harvey, 2005; Murdoch, 2006). However, this is just one of many spatial ontologies available within the social sciences (Merriman et al., 2012), and CCT scholars have recently begun to question their working assumptions about space (Chatzidakis et al., 2018). Rejecting the container metaphor of Euclid and Descartes, they have been inspired instead by the relationality of Liebniz and the relativity of Einstein (Harvey, 2005). Rather than 'space', CCT scholars have started to think and write in terms of spatiality, a more active or processual term that theorizes spatial dimensions as relational effects rather than objective antecedents (Massey, 2005; Murdoch, 2006). As a simple example, a room is large or small because of 
the contingent spatial relationships between four walls, a ceiling, and a floor. If the distances between these elements are rearranged, then the room is also altered. As Doel (2007, p.810) evocatively explains, spatiality "is continuously being made, unmade, and remade by the incessant shuffling of heterogeneous relations, its potential can never be contained".

Spatiality is thus unidentified and unbounded, just like space, but it represents a more active understanding whereby spatial arrangements can exert an influence on social phenomena (Vicdan and Hong, 2018). Accordingly, it is associated with the notion that spatial arrangements shape markets and consumption "beneath the surface of salience" (Coffin, 2019, p.2). Although there are many theoretical traditions that address the subliminal influence of spatiality, CCT scholars have largely been inspired by Thift's (2008) Non-Representational Theory (NRT), which can be used to explore the precognitive, affective, and atmospheric processes that shape sociospatial arrangements (Hill et al., 2014; Hill, 2016). NRT has inspired Canniford et al. (2018) to consider how smells play an important role in embodied experiences, but in ways that often operate beneath the cognitive-cultural radar of representation. Similarly, Cheetham et al. (2018) studied territorialization in public parks, stimulated by NRT to expand the analysis beyond conscious reflection and even human placemakers to a wider kaleidoscope of territorial negotiations. Spatiality emphasises the precognitive and subliminal while emplacement and place-making remain more closely associated with cognitive deliberation and explicit cultural representations. Meanings matter and perimeters play a role, but there are a number of unnoticed and fuzzy forces as well (Hill et al. 2014; Coffin, 2019).

What is worth emphasizing here is how NRT challenges the assumption that meaningful places are more relevant to managers than meaningless space. Although the term 'space marketing' may be somewhat nonsensical (as discussed above), spatial management makes sense when one acknowledges how spatiality can influence market actors subliminally. Hill (2016) provides a case study of spatial management in his account of soccer matches in the United Kingdom. Although documents, images, and other representations certainly played a role in shaping a sense of place, thinking non-representationally highlighted how positive and negative affects were passed contagiously between fans in close proximity. In the past these affects became intense and led to drunken revelry and violent clashes, but over time techniques were developed by police officers and soccer associations in order to manage the flow of bodies and thus the mood of match days. Given the commercial value of the soccer industry, such spatial management is closely entwined into marketing management. Hill's (2016) study provides evidence to suggest that the more 'spatial' sensibilities of NRT can help to provide a more fully-fledged understanding of match days and other market phenomena. The argument for spatial thinking was developed more explicitly by Coffin (2019), who proposed that marketers should look 'between', 'beneath', and 'beyond' particular places in order to develop a theorization of market spatiality that encompasses a broader range of phenomena than that usually incorporated into the place concept (e.g. conscious and unconscious, human and nonhuman, static and mobile).

If spatial sensibilities have the potential to revolutionize certain areas of marketing, elsewhere they will simply resonate with established assumptions. Marketing scholars who draw heavily on environmental psychology already assume that "even those changes to environmental stimuli that are not noticed, or consciously perceived by the consumer, are capable of causing shoppers to change behaviours while in the store" (Turley and Chebat 2002, p.125). A key contribution of CCT is to take these experimental and quasi-experimental insights 'beyond the store', just as psychosocial scholars look 'outside the clinic' (Frosh, 2010). As a case-in-point, Chatzidakis et al. (2012) acknowledged how more frequent street intersections in the Athenian district of Exarcheia allowed information and bodies to travel more quickly, evade police control more easily, and therefore contribute to the anarchic identity of this neighborhood. Their study also observes another source of the neighborhood's anarchic and heterotopic identity which may operate "beneath the surface of salience" (Coffin, 2019, p.2); namely, feelings of tension and excitement that are experienced more unconsciously (Chatzidakis, 2017), echoing psychogeographic (Debord, 1955) and psychoanalytic (Pile, 1996) theorizations of space. Although recent research on retail atmospherics has begun to consider "outdoor atmospherics" (Bloch and Kamran-Disfani, 2018) and "out of store" touchpoints (Roggeveen et al., 2020), clearly more could be done to develop market spatial thinking beyond the boundaries of the store environment.

Geomarketers have shown how a store's location may have a tremendous impact on shopping behaviour (Cliquet, 2013), but one might also consider the reverse influence of stores affecting the surrounding neighborhood's prestige, liveliness and walkability (Bloch and Kamran-Disfani, 2018). As noted above, CCT researchers have shown how contrasts between a site and its surroundings can create an otherworldly experience for consumers crossing the perimeter (Maclaran and Brown, 2005; Chatzidakis et al., 2012). The reverse is also true. For instance, CCT studies of flagship stores have noted the important symbiotic relationship between a prestigious store and an equally prestigious surrounding environment (Peñaloza, 1998; Borghini et al., 2009). Experimental and quantitative research could develop these insights further. Take Amell et al. (2015), who found that the relationship between street width and building height may contribute to feelings of comfort and "enclosure" that 
are conducive to customer approach rather than avoidance. Retailers and other marketing practitioners may therefore benefit by considering and, where possible, altering the environments surrounding their stores and other spatial assets. Ultimately these alterations will have to operate within specific geographical, architectural and regulatory constraints, so research that facilitates collaborations with urban planners, government agencies, and other not-for-profit actors would be beneficial.

Research that can contribute to attempts to build a coalition of spatial stakeholders will be increasingly important in an era of ecological crises (Care Collective, 2020). Spatiality is an especially relevant concept here in that it also speaks to the interests of posthuman thinkers and activists. This is because spatial sensibilities encourage scholars (and others) to look beyond human place-making (Coffin, 2019), thus facilitating an exploration of how non-humans, such as animals or smart objects, might experience spatial arrangements and contribute to human place-making (Coffin, forthcoming). Such ideas may become more mainstream as store designers, place marketers, and everyday consumers begin to reconsider how their decisions impact on wider ecological systems. Indeed, while 'posthuman' may be a somewhat esoteric label, it describes interests that are shared by researchers and practitioners operating with other disciplinary and sub-disciplinary terminology. Urban ecologists, as just one illustrative example, are generally committed to achieving some form of equilibrium in the urban "ecosystem", maximizing human and environmental benefits in the process (e.g. Alberti, 2008; Forman, 2014). Tactical thinking might encourage one to consider how transdisciplinary projects might apply concepts from urban ecology to inform servicescape design (Bitner, 1992), to create places that facilitate more ethical consumption (Chatzidakis et al., 2012), or alter place marketing to consider animal welfare (Coffin, forthcoming). Spatiality is a transdisciplinary concept that may allow posthumanists, urban ecologists, and many others to work toward a shared understanding that benefits all sorts of stakeholders, human or otherwise.

\section{From spatiality to implacement}

After passing spatiality the Möbius strip begins to curve back toward place and emplacement, but from a different direction that makes a significant difference. Here the move from spatiality becomes implacement (Casey, 1993). Although some scholars treat emplacement and implacement as synonymic, this would be to overlook the subtle nuances between the two terms. As Andéhn et al. $(2019$, p.3) outline, implacement "denotes what one's being in place means... through the subject's historical relations to place". Therefore, while emplacement suggests a pro-active choice to ephemerally gather people, products, and practices in a particular place (Bradford and Sherry, 2018), implacement points to lingering associations that cannot simply be abandoned or dismissed at will (Andéhn et al., 2019). This suggests a different understanding of the space-place relationship, one akin to De Certeau's (1984, p.117) conceptualization where "space is composed of intersections of mobile elements" and "a place is the order (of whatever kind) in accord with which elements are distributed in relationships of coexistence [...] it implies an indication of stability". This definition seems to accord with the tacit understandings shared by place marketing practitioners-after all, what is a place brand other than an attempt to stabilize (generally but not exclusively) positive associations to create an attractive biography of an otherwise ever-changing geography (Brown, 2018)? It may also be thought of as the implicit basis of atmospherics (Kotler, 1973) and servicescape design (Bitner, 1992), insofar as both seek to create carefully controlled environments. However, De Certeau's (1984) conceptual contradistinction seems somewhat at odds with the consensus in CCT, where space is presented as the less active partner in the pair (Visconti et al., 2010).

From a CCT perspective the crucial innovation is that implacement emphasises issues of ideology and institutionalism (Andéhn et al., 2019). This stimulates a more critical reading of place-making as a process of solidifying spatial, social, and symbolic arrangements into ossified images and identities. Geographical ossifications may become resources that individuals and groups use to anchor their sense of self (Castilhos et al., 2016), but they can also trap individuals and groups into pre-existing associations, putting them 'in place' without their consent. As the geographer David Harvey (1993, p.4) once noted, "we express norms by putting people, events and things in their proper place and seek to subvert norms by struggling to define a new place from which the oppressed can freely speak." The concept of implacement refocuses attention onto those who struggle to shed the sociosymbolic consequences of spatial associations (Andéhn et al., 2019), such as international migrants or those who grew up in 'the wrong part of town'. Places can serve an important symbolic function in communicating the identity of individuals and groups, but for some there is also value in anonymity (Coffin, 2019). To date, there has been limited marketing research in this area, save for a few fleeting examples given in empirical data. To cite one such example, Visconti et al. (2010) mentions the importance of anonymity for street artists in their study of public place. Yet, there remains a need to consider why consumers and other market actors might seek to escape from implacement and how they might achieve this. A first step, theoretically-speaking, is to invert the positive associations of place, treating it instead as "the reproduction of economic or sociocultural phenomena and their situatedness within specific locations", and to value space/ 
spatiality more highly as "associated with the idea of being in motion and becoming" (Giovanardi and Lucarelli, 2018, p.149). This can then be followed by empirical studies of spatial arrangements that afford freedom for implaced individuals and groups.

Linking place with the term reproduction hints at the ideological character of place-making as an institutional process: places implicitly further and favour established interests at the expense of alternatives, whereas spaces open up to new opportunities. Approaching from this side of the strip therefore suggests a more critical approach, one where the premises of place marketing and other forms of place-making are not taken-for-granted but rather subjected to academic scrutiny. Compare Diamond et al. (2009), who studied how flagship stores can be used to bring together various elements into a cohesive 'brand gestalt', and Borghini et al. (2009), who took a more critical approach by studying how such stores encourage profitable consumer activities and thus materialize pro-capitalist ideologies. Both papers emerged from the same research team and addressed the same empirical context, American Girl Place, yet their style of theorizing differed dramatically. Looking at the Möbius strip, the work of Diamond et al. (2009) reads more as a study of brand emplacement with clear managerial implications, while Borghini et al. (2009) is a more critical reading of implacement whose implications may be more relevant to policy-makers and pro-active consumers.

Several CCT studies might be located alongside Borghini et al. (2009) thanks to their critical stance, but also due to their focus on critical actors in the market: Thompson and Arsel's (2004) study explores the hegemonic impact of Starbucks on the aesthetics and social purposes of coffee consumption and how this is resisted by anticorporate consumers and local independent producers; Chatzidakis et al. (2012) show how radical activists may even go further by burning down and vandalising stores that are symbolic of global capitalism; Roux et al. (2018) explore how the sidewalk can be transformed during Bulky Item Collection days, creating temporary sites of exchange so unlike traditional in-store experiences that they can encourage passers-by to question consumerist values. In recent years consumers and marketers have become far more critical in response to issues like climate change, animal welfare, and modern slavery (Carrington et al., 2020), suggesting that the notion of implacement may become more prominent in the years and decades to come.

Despite the growing criticality of consumers and other market actors, mainstream marketing scholars only tend to think critically about theoretical frameworks, research designs, or data sets. Critiques of the capitalist system are far rarer. Yet, even if they continue to accept and endorse the system itself, mainstream studies of market spatiality may find the notion of implacement useful to challenge the less favourable consequences of capitalism. To illustrate this point, consider the finding that lowering the volume of in-store music/noise can increase sales of healthy food by making customers more relaxed (Biswas et al., 2019). CCT scholars and mainstream marketers might share the critical impulse to use this insight in order to dissolve unhealthy implacements and engender more healthy alternatives, especially given the relative ease with which store managers can manipulate volume levels. Implacement may also inspire larger-scale projects. As aforementioned, Rosenbaum (2009) argued that carefully designed sensory environments can be therapeutic for those with ADHD. In this vein, future transdisciplinary research may seek to consider how servicescapes may be entirely redesigned to alleviate other psychological conditions, like loneliness (Rosenbaum et al., 2007) or stress (Johnstone and Todd, 2012), and social issues, such as homelessness (Eckhardt and Dobscha, 2019).

The choice to critique only the negative consequences of capitalism is a political and ideological one, as is the choice to criticise capitalism as a system. The Möbius strip does not promote a particular stance but presents them as two positions along the same plane-differing greatly but capable of dialogue-and suggests that a tactical approach may be beneficial. The burgeoning literature on critical place marketing provides empirical proof that these different approaches to criticality can co-exist. On the one hand, scholars in this area have critiqued place marketing campaigns for displacing less profitable residents and businesses; on the other hand, they seek to work with place marketing managers to develop more 'inclusive' campaigns and initiatives (Warnaby and Medway, 2013; Giovanardi et al., 2019). Here the oscillation between seemingly opposing orientations can lead to theoretical developments but also policy recommendations and changes in managerial practice, enabling critical academics to produce impactful research in collaboration with powerful non-academic partners. The open question is how other transdisciplinary topics within market spatiality, from place attachment (Debenedetti et al., 2014; Rosenbaum et al., 2017) to customer journeys (Thomas et al., 2020; Grewal and Roggeveen, 2020), might also benefit from this collaborative style of critical scholarship. Thinking critically one might also ask: are there any drawbacks to adopting such a compromising approach?

\section{Displaced from markets...or displacing markets?}

As suggested by the example of critical place marketing, interest in ideological and institutional implacement also draws attention to the closely-related concept of displacement (Giovanardi et al., 2019). Critical place marketers have highlighted empirically how spatial stakeholders may be displaced by those who are more likely to engage in profitable 
activities (Warnaby and Medway, 2013; Castilhos, 2019). Yet, while place marketers tend to focus on larger-scale geographical entities like cities or regions, CCT studies have also shown these displacements at work at smaller scales by studying consumers who struggle to access market places at all or find themselves forcibly removed if they do manage to secure access (Castilhos, 2019). Physical displacement excludes individuals from the material and symbolic resources required to be a consumer, which is particularly problematic in consumerist societies (Saren et al., 2019). While scholars working in the critical tradition of place marketing have been most vocal about the 'dark side' of spatial marketization (see Castilhos, 2019), issues like 'service inclusion' have begun to emerge in the marketing mainstream also (Fisk et al., 2018). If the similarities between these different concepts can be foregrounded, scholars of varying backgrounds and interests can work toward a shared aspiration of helping displaced consumers.

Displacements that are not so obvious to third parties may yield equally disastrous results. Maclaran and Brown (2005) documented how the festival mall of Powerscourt was refurbished in order to attract new customer segments. The old environment had created a 'utopian' experience of otherworldly escape that was highly valued by a loyal group of consumers. The renovation dissolved these utopian qualities and left these consumers feeling displaced. Maclaran and Brown's (2005) research demonstrates that displacements may involve physical movement but also cognitive and cultural changes. In other cases, displacements may not involve change but instead take a more chronic form. Regany and Emontspool (2015) show how ethnic minority consumers experience supermarkets as sites of exclusion and marginalization when marketing managers 'take them for fools' by commodifying their cultures incorrectly or insensitively. These consumers are physically located within the market-place (in order to make some necessary purchases), but they are psychologically and socially displaced by the experience.

The notion of psychosocial displacement may also be applied to the aforementioned studies of consumers who feel 'out-of-place' (e.g. Allen, 2002; Sherry et al., 2004). These studies highlight how feeling displaced can lead consumers to pro-actively place themselves somewhere more suitable. In order words, the disempowerment of displacement is very close to the empowerment of emplacement. A crucial question for future transdisciplinary research is how displaced consumers can be transformed into consumers capable of their own emplacement. CCT scholars have shown that only certain consumers have the economic, social, or cultural capital to be able to move freely (Bardhi et al., 2012; Bardhi and Eckhardt, 2017), but these insights are generally ignored in mainstream accounts of customer journey (Thomas et al., 2020; Grewal and Roggeveen, 2020) and experience (e.g. Verhoef et al., 2009; Roggeveen et al., 2020) because these studies focus on consumers who have already been able to access the site in question. Displaced consumers have been precluded by conceptual and methodological decisions in extant studies, but as exclusion and inclusion are moving up the agendas of marketing academics from multiple disciplinary backgrounds (e.g. Saatcioglu and Ozzane, 2013; Fisk et al., 2018; Castilhos, 2019; Giovanardi et al., 2019; Hutton, 2019) it is likely that displacement will represent a fecund area of future research.

Although the term displacement may refer to those pushed out of place, whether psychosocially and/or physically, it may also refer to the deterritorialization of people, practices, products, and other phenomena into more nomadic forms (Bardhi et al., 2012). In other words, displacement refers to a process of transforming something place-bound into something no longer determined by place, such as the displacement of community by communication technologies (Anderson, 1983; Muñiz and O'Guinn, 2001). These alternative understandings can be figuratively framed as crossing the 'twist' in the Möbius strip, but this time from the other side of the plane. Just as place shaded into emplacement, this twist represents how these two understandings of displacement are simultaneously similar and dissimilar. This twist also allows a return to the starting point of space. Recalling that place-making practices are characteristically territorial, the de-territorializations of displacement represent a mirror-image to the space-place relationship. As argued above, nothing can become entirely 'placeless' or 'aspatial' (Chatzidakis et al., 2018). However, the relationships between social, symbolic, and spatial phenomena can certainly become more fluid (Bardhi et al., 2012).

Displacement may be applied to many market-spatial phenomena, but none is as pertinent as the market itself. Whereas once a 'market' was a specific site in each town or city where people came to trade (e.g. the agora), the onset of modernity deterritorialized the market into more pluralistic and abstract forms (Guattari, 1989; Roffe, 2016). The logics of markets are now applied to almost every area of contemporary life (Kozinets, 2002; Eckhardt and Bardhi, 2016). This can be clearly seen in public space, such as streets and squares increasingly given over to commercial frontages and advertising billboards, but is also resisted through local territorial practices, such as street art (Visconti et al., 2010). Such everyday acts of resistance can be thought of as acts that generate parasitic heterotopias, spaces of 'otherness' within quotidian environments, operate beside the dominant market logics of commercial exchange, and inspire critical thinking by creating a temporary arrangement that is somewhat alien to the geographical body (Roux et al., 2018). Mainstream marketers may use this concept to re-analyse their own data sets, discerning inconspicuous moments of resistance in seemingly mundane arrangements of market spatiality-consumers rearranging chairs 
in Starbucks may be read as an act of idiosyncratic appropriation (Venkatraman and Nelson, 2009) or as an act of resistance in the face of a hegemonic brandscape (Thompson and Arsel, 2004). As ever, the Möbius strip recommends a tactical approach that incorporates multiple readings.

Despite local resistance, markets continue to deterritorialize. Cuts to government funding have forced art galleries and other social organizations to adopt a more consumer-centric approach to their operations, which in turn affects the environments that they create for their key stakeholders (Ekström, 2019; Panozzo, 2019). Similarly, Airbnb and other property-renting platforms encourage property owners to displace personal place attachments in order to monetize their spaces (Miles, 2018; Roelofsen and Minca, 2018). In the face of such trends, CCT scholars have found Lefebvre's (1991) notion of 'abstract space' helpful (Saatcioglu and Ozzane, 2013; Vicdan and Hong, 2018). The etymological root of abstraction is the Latin abstractus, "meaning to draw away from" (Roffe, 2016, p.49), and as noted by Saatcioglu and Ozzane (2013, p.33), space is abstracted when it is "measured, mapped, and generally devoid of social or cultural meaning [...] allowing space to have the exchange value that is essential for the movement of capital." Marketization encourages the displacement of meaningful places in favour of more malleable spaces (e.g. Maclaran and Brown, 2005), especially as consumers who are attached to places actively resist change (Debenedetti et al., 2014). From a managerial perspective this suggests that each store, neighbourhood, or other place may possess an optimal level of 'stimulation', with higher and lower intensities having a negative effect on shopping behaviours (Bloch and Kamran-Disfani, 2018). The transdisciplinary question becomes: when and where is place-making desirable?

\section{Analyzing atmosphere: an illustrative trip along the strip}

The previous sections have demonstrated how the Möbius strip of market spatiality provides an "integrated understanding of the phenomena of interest" (Vargo and Koskela-Huotari, 2020, p.2). They have drawn together literature from across marketing theory and practice, seeking to emphasize how the Möbius strip may mobilize conversations and collaborations across disciplinary or subdisciplinary divides. This section seeks to develop another useful function of the Möbius strip-the analysis of a single topic from a range of different positions-by exploring how CCT scholars and mainstream marketers account for the phenomenon of atmosphere.

As noted by Kotler (1973, p.50), "one hears a restaurant described as having an atmosphere [...] as having a "good" atmosphere or "busy" atmosphere or "depressing" atmosphere." However, although the word atmosphere is widely used and understood, this is not to suggest that it is a simple phenomenon that can be easily explained from one disciplinary tradition. Rather, marketing theorists have demonstrated that a variety of theoretical approaches are needed to fully understand the multi-sensory, multisited, and multi-directional character of atmospheres (e.g. Steadman et al., 2020). Understanding atmosphere may also be particularly important for managerial audiences; Kotler's (1973) early example of atmospherics was a restaurant and this has been followed by a substantial range of applications since (e.g. Spence et al., 2014; Roggeveen et al., 2020). More recent CCT research adds that consumers and other actors may make atmospheric alterations to their own ends (e.g. Maclaran and Brown, 2005; Debenedetti et al., 2014; Hill, 2016). Thus, a fuller understanding of atmospheres may produce a range of theoretical, managerial, and societal implications.

As a point of departure, it is worth positing that the concept of atmosphere is more closely aligned to space. An atmosphere is the je ne sais quoi quality of an environment, often keenly felt but difficult to identify or describe (Hill, 2016). One approach to understand an atmosphere is to break it down into its component parts, such as the sensory elements of visual, auditory, olfactory, gustatory, and tactile stimuli (Kotler, 1973). These stimuli can then be isolated through experimental research designs, testing how each aspect of an atmosphere may influence consumers' experiences and behaviours (Baker et al., 1992; Turley and Milliman, 2000). Another approach is to conceptualize an atmosphere holistically, treating it as a whole that is greater than the sum of its parts. Here the notion of atmosphere is similar to the genius loci, or 'spirit of place', and best understood through detailed analyses of first-hand accounts from consumers and consumer researchers (Maclaran and Brown, 2005; Sherry, 2013). This holistic conceptualization of atmospheres might be located somewhere between space and place, insofar as market actors can describe a particular atmosphere but only in an imprecise way. This contrasts with fully-fledged placemaking projects like a place branding campaign, which seek to create a geographical biography and communicate the benefits of visiting the place in question (Brown, 2018), but also the entirely anonymised conceptualization of space as unknown or undefined (Visconti et al., 2010).

Methodologically the Möbius strip would suggest combining discursive data (e.g. consumers describing atmospheres in interviews) with observational data that do not rely on representations (e.g. comparing variations of in-store music tempo with changing sales patterns) in order to fully understand how atmospheres emerge, evolve, and exert effects within a given site. Methodological pluralism may also be advantageous for practitioners. In place marketing similar transdisciplinary dialogues have already generated a call for a more multisensory approach to place branding, seeking to expand marketing 
materials beyond their presently ocularcentric focus on words and pictures (Medway, 2015; Henshaw et al., 2016). Whilst recognizing the methodological and practical difficulties of such a task, Medway and Warnaby (2017) argue that the theoretical and managerial benefits are worth the effort. The scholarship on in-store atmospherics, which is ahead of the multisensory curve and has demonstrated the value of thinking beyond sight and sound (Spence et al., 2014), adds credence to this argument but also provides a body of literature that might be a fruitful interlocutor for place marketers, CCT scholars, and others. Thinking 'tactically' (Frosh, 2014), it may be argued that moving the concept of atmosphere along the Möbius strip between space and place may help to provide a more sophisticated understanding that would benefit academics of various disciplinary denominations, as well as non-academic stakeholders of various stripes.

In addition to combining different methodological approaches, a fuller understanding will require theorizations that attempt to accommodate those atmospheric phenomena that are difficult, if not impossible, to represent in language or imagery (Hill et al., 2014). Although CCT scholars have been the primary proponents of the 'non-representational' rhetoric (e.g. Canniford et al., 2018), a more mainstream formulation is the distinction between "affective" and "cognitive" phenomena (Spence et al., 2014). As such, a more tactical approach to terminology may help to emphasize similarities and encourage scholars from different backgrounds to appreciate one another's insights about atmospheres. For instance, while the affective/cognitive distinction may share much in common with nonrepresentational theorizations, the latter also points toward other manifestations of atmosphere that are novel to the former. Hill's (2016) non-representational study of 'mood management' is a case-in-point, showing how crowds of sports fans create moving atmospheres that must be carefully harnessed in order to maximise commercial conviviality but also avoid violence and thuggery. This is quite unlike the in-situ studies of store atmospherics (e.g. Kotler, 1973; Spence et al., 2014) or even earlier CCT studies of spaces and places (e.g. Maclaran and Brown, 2005; Debenedetti et al., 2014).

On the Möbius strip of market spatiality this means flipping over the plane from space to spatiality and from place to implacement. The atmospheres being described by Hill (2016) are mobile and mutable, à la spatiality, but as these are also atmospheres that 'follow' the participants then they have lingering effects that transcend a particular place, echoing the notion of implacement. If atmosphere can describe both the genius loci of a specific site but also the lasting affects carried between sites (Hill et al., 2014), thinking tactically about atmospheres means swivelling the strip to consider locality and mobility, ephemerality and institutionalization. Such swivelling might be retrospectively applied to extant studies, such as the work of Chatzidakis et al. (2012): they described how the arrangement of the physical space allowed riots to spread easily through Exarcheia as spatial flows of bodies and moods, contributing to the anarchic sense of place and thus attracting and retaining those who identified with this implaced ideology. Multiple studies may also be integrated together: Amell et al. (2015) demonstrate that outdoor shopping areas are often designed in ways that subliminally reproduce an atmosphere of safety and enclosure, building on the earlier work that designers of shopping areas should make "pleasing" places (Alexander et al., 1977) with definitive shapes and walls that resemble the safety of one's own home. The archetypal place of 'home' serves as an institutional implacement that shapes how many commercial atmospheres are evaluated, as shown by studies of emplacement drawing on the consumercentric CCT tradition (Debenedetti et al., 2014; Bradford and Sherry, 2015) but also more managerially-oriented scholarship (Rosenbaum et al., 2017).

Understandings of atmosphere may also be enriched by considering emplacement. Emplacement evokes consumers and other spatial stakeholders adopting a pro-active approach to choosing and using sites (Bradford and Sherry, 2018). When actors gather together in an area their 'structural alignments' create a dialectical relationship whereby the group and the site are both transformed (Thomas et al., 2013). Mainstream marketers have recognized the important role of people in creating spaces and places, but generally they emphasize the agency of store designers, managers, and employees (e.g. Bitner, 1992). Using the terminology of the Möbius strip, these actors may be described as 'placemakers'. In contrast, CCT scholars tend to balance these against the interpretations and appropriations of consumers (Kozinets et al., 2004; Maclaran and Brown, 2005; Venkatraman and Nelson, 2009). Thus, while place-makers make important contributions to an atmosphere, especially when they follow Kotler's (1973) suggestion to consciously design an atmospheric, it must be noted that atmospheres also emerge from the pro-activities of consumer emplacements. Everyday experience demonstrates that a store without customers tends to lack atmosphere, except perhaps the eerie atmosphere of an abandoned ruin (Warnaby and Medway, 2017). Furthermore, CCT research has demonstrated that unconventional consumption can make a commercial site more unique (Maclaran and Brown, 2005; Debenedetti et al., 2014). The managerial implication of emplacement is that different kinds of consumer and differing consumption practices may alter the atmosphere of an environment in ways that deviate from managerial design. For instance, although "neighbourhood richness" is often viewed as a positive feature of a store's location, too much stimulation by other consumers and activities may distract or avert them from actual shopping, undermining managerial control over their customers' journeys (Bloch and Kamran-Disfani, 
2018). On the other hand, "lifestyle hotels" such as ACE hotel are heavily based on customer-customer interactions, but managers have greater capacity to control and moderate this sociality with a range of carefully-designed experiential activities that resonate with the principles of emplacement but retain a commercial focus (e.g. Cheng et al., 2016).

The Möbius strip serves as a reminder that that these emplacements should be considered alongside spatiality and implacement. In regard to spatiality, scholars have shown the subliminal influences of spatial arrangements from a variety of theoretical perspectives (Turley and Milliman, 2000; Turley and Chebat, 2002; Hill et al., 2014; Coffin, 2019). If empirical research suggests that manipulating factors like music tempo or ambient smells can affect customer's moods and activities, most notably sales (Milliman, 1982, 1986; Sprangeberg et al., 1996, 2005; Knoferle et al., 2012), then this adds nuance to the concept of emplacement by suggesting that scholars should look beneath, between, and beyond moments of conscious decisionmaking in order to fully understand emplaced phenomena (Coffin, 2019). CCT studies add that such subliminal spatial influences also operate outside of stores, when people are not playing the role of 'shopper' but rather that of residentactivists (Chatzidakis et al., 2012), football fans (Hill, 2016; Steadman et al., 2020), or park user (Cheetham et al., 2018). Here CCT studies of spatiality may find a fruitful dialogue with mainstream areas of inquiry like "outdoor" atmospherics (Bloch and Kamran-Disfani, 2018), but generally mainstream marketers have focused on the less conscious influences found within store atmospheres (e.g. Dijksterhuis et al., 2005; De Luca and Botelho, 2019), so out-of-store atmospheres remain a fruitful area for transdisciplinary collaboration.

In terms of implacement, CCT scholars have long noted that commercialized environments can "have a narrative design that also directs the course of consumers' mental attention, experiences, and related practices of self-narration" (Arnould and Thompson, 2005, p.875). These narratives are partially created by the brand (Borghini et al., 2009), but primarily they are drawn from the prevailing culture (Maclaran and Brown, 2005). Such cultural influences have been acknowledged in the literature on customer journeys, but these studies have typically drawn on Hofstede's definition of culture (Grewal and Roggeveen, 2020). CCT provides a more complex theorization of culture than Hofstede (Arnould and Thompson, 2005), and may therefore help to appreciate how atmospheres are created by an interplay of emplacements and implacements as consumers journey through a particular service environment. In turn, the concept of the customer journey helps to translate the CCT work on emplacement (Bradford and Sherry, 2018) into a more managerially-relevant context (Thomas et al., 2020), thus creating another opportunity for potential transdisciplinary collaboration. A connection back to spatiality may also be made thanks to recent research on "out of store retail journey touchpoints" (Roggeveen et al., 2020), suggesting that consumer journeys need not remain contained to an in-store environment.

Finally, a conceptualization of atmosphere will be rounded off by considering displacement and connecting back to the starting point of space. The notion of displacement raises the question of how an atmosphere might be deterritorialized in ways that allow it to be replicated (at least in part) elsewhere. First, although most studies of atmospherics focus on stores as carefully controlled commercial settings (Kotler, 1973; Spence et al., 2014), the insights of these studies can be transferred to other environments such as airports (Hietanen et al., 2016; Moon et al., 2017), or river rafting experiences (Arnould et al., 1993) and other "outdoor" atmospherics (Bloch and Kamran-Disfani, 2018). Second, the emergence of themed environments shows how managers and consumers value the ability to 'capture' an atmosphere and recreate it elsewhere. One high profile example is Hollister, which seeks to recreate the ambience of a Californian beach hut (Brown et al., 2018), but transdisciplinary studies of Mexican restaurants (Campbell, 2005; Muñoz and Wood, 2009) and Irish Pubs (Muñoz et al., 2006; Patterson and Brown, 2007) provide other illustrations of atmospheres that are deterritorialized from one place and reterritorialized in countless other sites. As shown by the mainstream literature on Country-Of-Origin effects, products and services also seek to evoke the atmospheres of certain geographies in order to appeal to consumers (Andéhn et al., 2016; Rashid et al., 2016). Connecting back to the interests of implacement, the ideological question becomes whether these innumerable commercial connections to countries and other places makes it more difficult for individuals to freely define their own identity (Andéhn et al., 2019). Indeed, certain sites may be defined by refusing to reterritorialize a typical atmosphere, such as independent coffee shops that are attractive to consumers because they are so unlike the dominant coffee shop template provided by Starbucks (Thompson and Arsel, 2004). Meanwhile, Venkatraman and Nelson (2009) detail how Chinese consumers use Starbucks but make small personal adjustments like rearranging seats, thus transforming the coffee shop template into a more idiosyncratic place for working or socializing. Both describe attempts to form local responses to the displaced atmospheres of global and generic environments: the former turns away from displacement toward novel place-making while the latter is evidence of consumer emplacement.

The displacement of atmospheres may also continue, eventually describing atmospheres that are akin to abstract space. Take the example of airports: Augé (1992) described them as non-places because they are rarely distinctive and share a very similar atmosphere. However, this is not to suggest that these spaces are innocuous. Hietanen et al., 


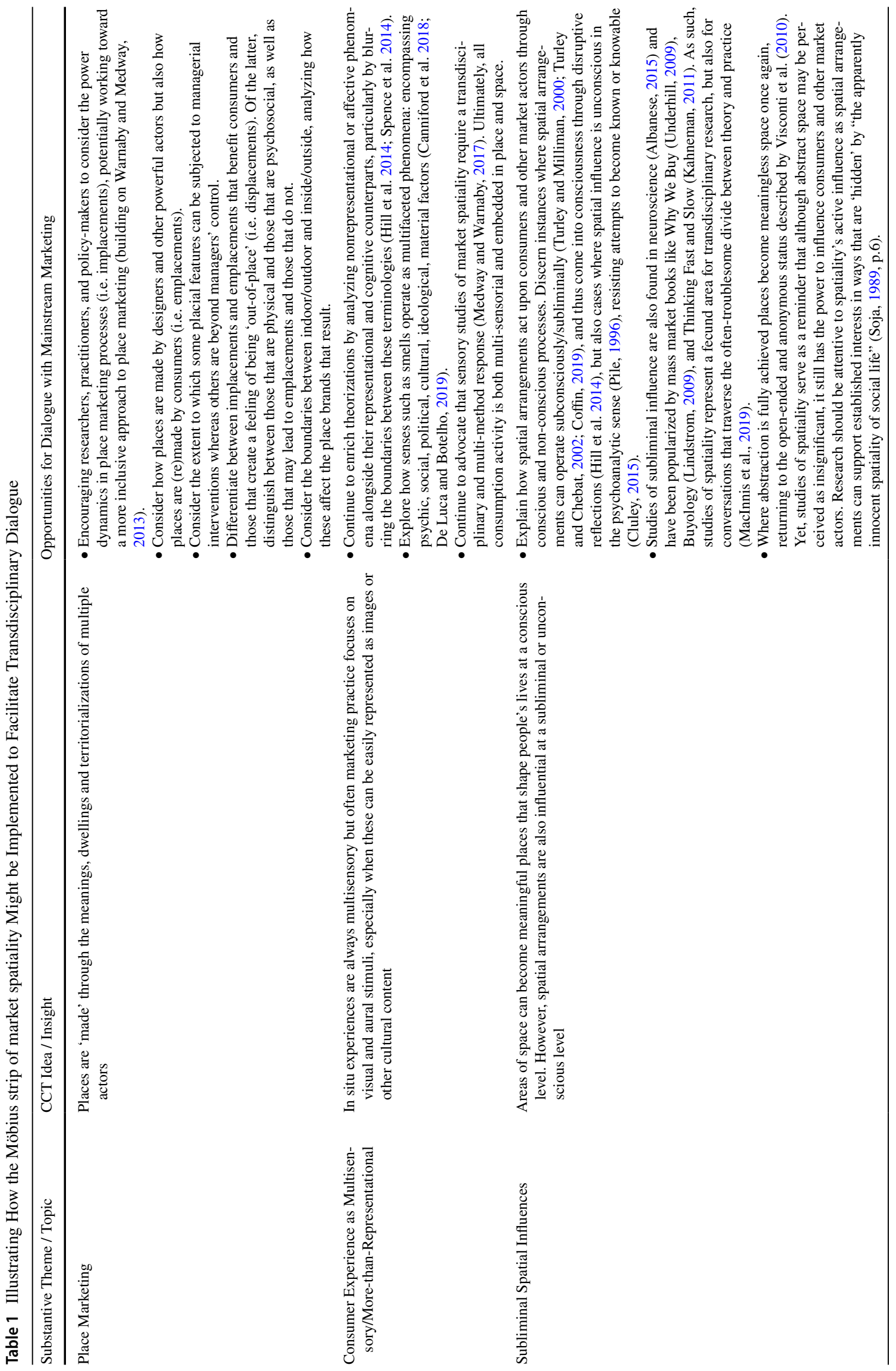




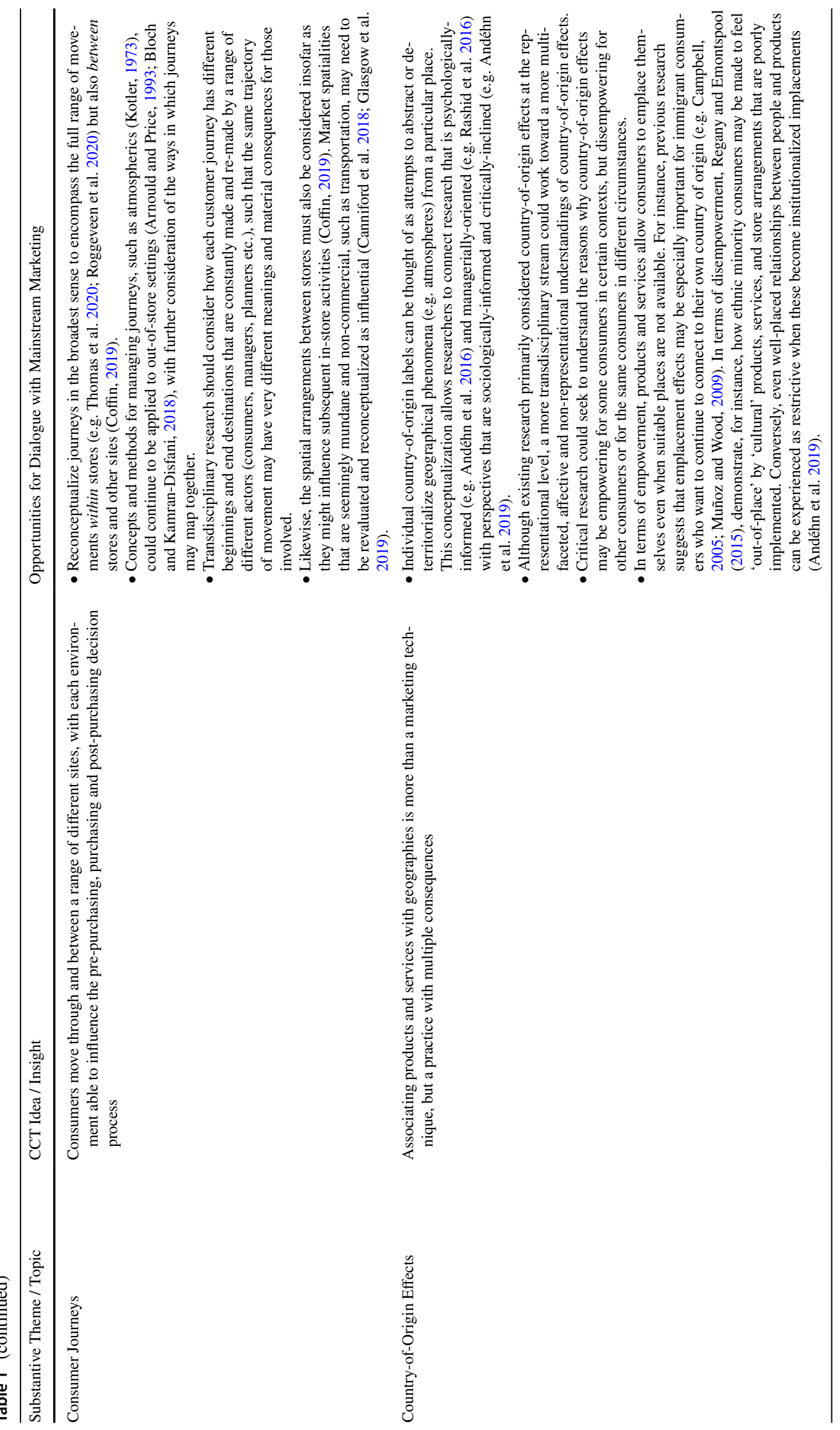


(2016) demonstrate how airports function as machines that condition bodies and reproduce social distinctions, implicitly reproducing ideological infrastructures like class and selfgovernance. Research such as this may lead to the conclusion that airports have abstract atmospheres, disassociated with any particular place (read: displaced) but still spatial arrangements that standardize sociosymbolic relations (a combination of spatiality and implacement). Thus, although space may be presented as inert when taken at face value, when combined with the other concepts on the Möbius strip a more critical stance may be adopted in relation to abstract atmospheres, which may appear more sinister when space is contrasted with spatiality, implacement, and displacement. Juxtaposing contrasting conceptual angles along the same strip may also highlight opportunities to resist the negative influences of abstract atmospheres and mobilize change. Critical scholarship on atmospheres may therefore wish to critique how most atmospheres are designed with managerial interests in mind, but it may also wish to help commercial actors to work with consumers, policy-makers, and other actors for the benefit of society. Here the quotidian example of transport is illustrative. For Augé (1992) cars and other methods of transport are also non-places. Yet environmental psychologists have shown how transport influences mood (Glasgow et al., 2019), reinforcing insights from recent nonrepresentational studies by CCT researchers (Hill, 2016; Canniford et al., 2018). Looking between stores and other managed places (Coffin, 2019), it might be argued that the mood-altering effects of transport atmospheres may be of interest to place marketers, bringing them into alignment with local governments and other non-profit stakeholders.

\section{Concluding remarks: mobilizing the Möbius strip}

As noted in the introduction, a simplistic reading of Arnould and Thompson (2005) would treat CCT as a discrete area of marketing scholarship, one that might even be considered 'at odds' with the marketing mainstream. The present paper subscribes to a more nuanced reading of the CCT-mainstream relationship as one characterized by distance rather than discreteness. Unlike the incommensurable differences implied by a paradigmatic framing (c.f. Kuhn, 1962), the Möbius strip suggests that the insights and ideas of different disciplines can be organised along a single theoretical plane. This is achievable, in part, because a Möbius strip is not tethered to any particular theoretical tradition, acting as an agnostic framework that can facilitate transdisciplinary theorizing (Frosh, 2014). Actor-network theory (Latour, 2005) and assemblage theories (Deleuze and Guattari, 1987; DeLanda, 2006) provide 'flat ontologies' that are similar to the Möbius strip in terms of integrating ideas. However, they necessitate philosophical commitments that create divisions between adherents and dissenters. In contrast, the Möbius strip does not impose a preferred philosophical paradigm and therefore facilitates dialogue across conventional disciplinary divides.

Integrating insights, ideas, and interests from diverse disciplines along a single strip will certainly be difficult, but the benefit of transdisciplinary thinking may outweigh the costs. As an ordering theorization (Sandberg and Alvesson, 2020), the value of the Möbius strip may be to reduce the costs and make the benefits more accessible. To be clear, this is not to suggest that the strip provides a single, synthetic theorization that can dissolve paradigmatic distinctions altogether. Rather, it seeks to create a single plane of theorization along which shared topics of interest can be arranged and alternative approaches can be broached through collaborative conversations. Scholars with incommensurable perspectives may not be able to overcome their differences, but they may benefit from tactically translating insights from other areas of research into the terminology and styles of thinking of their own, as shown in Table 1.

Mainstream marketing academics and practitioners were the intended audience of this paper. An ordering theorization can be especially useful for an audience unfamiliar with a particular area of research (Sandberg and Alvesson, 2020), and the primary purpose of this paper was to build a compelling case for the value of CCT scholarship on market spatiality for mainstream marketing audiences. However, CCT scholars can benefit from this Möbius strip, insofar as ordering theorizations help scholars to see familiar topics anew with novel distinctions or unexpected connections (Sandberg and Alvesson, 2020). As discussed above and distilled in Table 1, there may also be opportunities to bridge the theory-practice divide and engage with nonacademic audiences (MacInnis et al., 2019). In concluding, it is worth noting that the ordering theorization of the Möbius strip can also be applied to other transdisciplinary topic areas that matter to wide and varied audiences, such as sustainability or de-colonization (Arnould et al., 2019). In areas such as these, there is a pressing need to develop an "integrated understanding of the phenomena of interest" (Vargo and Koskela-Huotari, 2020, p.2). It is hoped that the Möbius strip may be helpful in mobilizing a more transdisciplinary and tactical approach to building knowledge for the benefit of all involved.

Open Access This article is licensed under a Creative Commons Attribution 4.0 International License, which permits use, sharing, adaptation, distribution and reproduction in any medium or format, as long as you give appropriate credit to the original author(s) and the source, provide a link to the Creative Commons licence, and indicate if changes were made. The images or other third party material in this article are included in the article's Creative Commons licence, unless indicated otherwise in a credit line to the material. If material is not included in the article's Creative Commons licence and your intended use is not permitted by statutory regulation or exceeds the permitted use, you will need to obtain permission directly from the copyright holder. To view a copy of this licence, visit http://creativecommons.org/licenses/by/4.0/. 


\section{References}

Agnew, J. (2011). Space and place. In: (Eds.) J. Agnew and D. Livingstone, Handbook of geographical knowledge, pp.316-331, SAGE, London, UK.

Albanese, P. (2015). The unconscious processing information. Marketing Theory, 15(1), 59-78.

Alberti, M. (2008). Advances in urban ecology: integrating humans and ecological processes in urban ecosystems (No. 574.5268 A4). New York: Springer.

Alexander, C., Ishikawa, S., \& Silverstein, M. (1977). A pattern language: towns, buildings, construction. New York: Oxford University Press.

Allen, D. (2002). Toward a theory of consumer choice as sociohistoricallyshaped practical experience: the fits-like-a-glove (FLAG) framework. Journal of Consumer Research, 28(4), 515-532.

Amell, S. H., Hamidia, S., Garfinkel-Castroa, A., \& Ewing, R. (2015). Do better urban design qualities lead to more walking in salt Lake City, Utah? Journal of Urban Design, 20(3), 393-410.

Andéhn, M., Nordin, F., \& Nilsson, M. (2016). Facets of country image and brand equity: revisiting the role of product categories in country-of-origin effect research. Journal of Consumer Behaviour, 15(3), 225-238.

Andéhn, M., Hietanen, J., \& Lucarelli, A. (2019). Performing place promotion - on implaced identity in marketized geographies. Onlinefirst: Marketing Theory.

Anderson, B. (1983). Immagined community. London: Verso.

Arnould, E., \& Thompson, C. (2005). Consumer culture theory (CCT): twenty years of research. Journal of Consumer Research, 31(4), 868-882.

Arnould, E., \& Thompson, C. (2015). Consumer culture theory: ten years gone (and beyond). Consumer Culture Theory (Research in Consumer Behavior), 17, 1-21.

Arnould, E., \& Thompson, C. (2018). Consumer culture theory. In F. Wherry \& I. Woodward (Eds.), Oxford handbook of consumption. Oxford, UK: Oxford University Press.

Arnould, E., \& Price, L. (1993). River magic: extraordinary experience and the extended service encounter. Journal of Consumer Research, 20(1), 24-45.

Arnould, E., Press, M., Salminen, E., \& Tillotson, J. (2019). Consumer culture theory: development, critique, application and prospects. Foundations and Trends in Marketing, 12(2), 80-166.

Arvidsson, A., \& Caliandro, A. (2016). Brand public. Journal of Consumer Research, 42(5), 727-748.

Aubert-Gamet, V., \& Cova, B. (1999). Servicescapes: from modern non-places to postmodern common places. Journal of Business Research, 44(1), 37-45.

Augé, M. (1992). Non-places: an introduction to anthropology of supermodernity. London: Verso.

Baker, J. (1987). The role of the environment in marketing services: The consumer perspective. In J. Czepiel, C. Congram, \& J. Shanahan (Eds.), The services challenge: Integrating for competitive advantage (pp. 79-84). Boston, MA: American Marketing Association.

Baker, J., Levy, M., \& Grewal, D. (1992). An experimental approach to making retail store environmental decisions. Journal of Retailing, 68, 445-460.

Bardhi, F., \& Eckhardt, G. (2017). Liquid consumption. Journal of Consumer Research, 44(3), 582-597.

Bardhi, F., Eckhardt, G., \& Arnould, E. (2012). Liquid relationship to possessions. Journal of Consumer Research, 39(3), 510-529.

Borghini, S., Diamond, N., Kozinets, R. V., McGrath, M. A., Muniz, A., Jr., \& Sherry, J. F., Jr. (2009). Why are themed brandstores so powerful? retail brand ideology at American Girl Place. Journal of Retailing, 85(3), 363-375.
Biswas, D., Lund, K., \& Szocs, C. (2019). Sounds like a healthy retail atmospheric strategy: effects of ambient music and background noise on food sales. Journal of the Academy of Marketing Science, 47(1), 37-55.

Bitner, M. (1992). Servicescapes: the impact of physical surroundings on customers and employees. Journal of Marketing, 56(2), 57-71.

Bloch, P. H., \& Kamran-Disfani, O. (2018). A framework for studying the impact of outdoor atmospherics in retailing. AMS Review, $8(3-4), 195-213$.

Bradford, T., \& Sherry, J. (2015). Domesticating public space through ritual: tailgating as vestaval. Journal of Consumer Research, 42(1), 130-151.

Bradford, T., \& Sherry, J., Jr. (2018). Dwelling dynamics in consumption encampments: tailgating as emplaced brand community. Marketing Theory, 18(2), 203-217.

Brown, S. (2018). Place brand biography: something special or same old story? In A. Campelo (Ed.), Handbook on place branding and marketing. Cheltenham, UK: Edward Elgar Publishing.

Brown, S., Stevens, L., \& Maclaran, P. (2018). Epic aspects of retail encounters: the Iliad of Hollister. Journal of Retailing, 94(1), $58-72$.

Campbell, H. (2005). Chicano lite: Mexican-American consumer culture on the border. Journal of Consumer Culture, 5(2), 207-233.

Canniford, R., Riach, K., \& Hill, T. (2018). Nosenography: how smell constitutes meaning, identity and temporal experience in spatial assemblages. Marketing Theory, 18(2), 234-248.

Care Collective (2020). The care manifesto. Verso, London \& New York.

Carrington, M., Chatzidakis, A., \& Shaw, D. (2020). Consuming worker exploitation? Accounts and justifications for consumer (in) action to modern slavery. Work, Employment and Society, forthcoming. https://doi.org/10.1007/0950017020926372.

Casey, E. S. (1993). Getting back into place. Bloomington: Indiana University Press.

Castilhos, R. (2019). Branded places and marketplace exclusion. Consumption Markets \& Culture, 22(5-6), 582-597.

Castilhos, R., Dolbec, P., \& Veresiu, E. (2016). Introducing a spatial perspective to analyze market dynamics. Marketing Theory, 17(1), 9-29.

Cayla, J., \& Eckhardt, G. (2008). Asian brands and the shaping of a transnational imagined community. Journal of Consumer Research, 35(2), 216-230.

Chatzidakis, A., Maclaran, P., \& Bradshaw, A. (2012). Heterotopian space and the utopics of ethical and green consumption. Journal of Marketing Management, 28(3/4), 494-515.

Chatzidakis, A., Morven, M., \& Warnaby, G. (2018). Consumption in and of space and place: introduction to the special issue. Marketing Theory, 18(2), 149-153.

Chatzidakis, A. (2017). Consumption in and of crisis-hit Athens. In D. Dalakoglou \& G. Aggelopoulos (Eds.), Greek crisis: critical ethnographic approaches and engaged anthropological perspectives (pp. 150-161). London: Routledge.

Cheetham, F., McEachern, M., \& Warnaby, G. (2018). A kaleidoscopic view of the territorialized consumption of place. Marketing Theory, 18(4), 473-492.

Cheng, J. S., Tang, T. W., Shih, H. Y., \& Wang, T. C. (2016). Designing lifestyle hotels. International Journal of Hospitality Management, 58, 95-106.

Cliquet, G. (2013). Geomarketing: methods and strategies in spatial marketing. John Wiley \& Sons.

Cluley, R. (2015). Consumption and repression. Marketing Theory, 15(3), 365-379.

Coffin, J. (2019). Deleuzoguattarian place marketing: becoming, between, beneath and beyond. Journal of place management and development. EarlyCite. 
Coffin, J. (forthcoming). Posthuman phenomenology: what are places like for nonhumans? In D. Medway, G. Warnaby, \& J. Byrom (Eds.), A research agenda for place branding. Edward Elgar Publishing, Cheltenham, UK.

Coffin, J., Eichert, C., \& Nolke, A. (2019). Towards (and beyond) LGBTQ+ studies in marketing and consumer research. In S. Dobscha (Ed.), Handbook of research on gender and marketing (pp. 273-293). London, UK: Edward Elgar Publishing.

Cresswell, T. (1992). In place / out of place. Minneapolis and London: University of Minnesota Press.

Cresswell, T. (2004). Place: a short introduction. London, UK: Blackwell.

Debenedetti, A., Oppewel, H., \& Arsel, Z. (2014). Place attachment in commercial settings: a gift economy perspective. Journal of Consumer Research, 40(5), 904-923.

Debord, G. (1955). Introduction to a critique of urban geography. In H. Bauder \& M. Salvatore (Eds), Critical geographies: a collection of readings (2008) (pp. 23-27). Praxis ePress. http://www.praxis-epress. org/availablebooks/introcriticalgeog.html

De Certeau, M. (1984). The practice of everyday life (trans: Rendall, S.). University of California Press, Berkeley, CA, and London, UK.

DeLanda, M. (2006). A new philosophy of society: assemblage theory and social complexity. London: Continuum.

Deleuze, G., \& Guattari, F. (1987). A thousand plateaus (trans: Massumi, B.). Athlone, London, UK.

De Luca, R., \& Botelho, D. (2019). The unconscious perception of smells as a driver of consumer responses: a framework integrating the emotion-cognition approach to scent marketing. AMS Review, Available at: . https://doi.org/10.1007/s13162-019-00154-8.

Diamond, N., Sherry, J., Muñiz, A., McGrath, M., Kozinets, R., \& Borghini, S. (2009). American Girl and the brand gestalt: closing the loop on sociocultural branding research. Journal of Marketing, 73(3), 118-134.

Dijksterhuis, A., Smith, P., van Baaren, R., \& Wigboldus, D. (2005). The unconscious consumer: effects of environment on consumer behaviour. Journal of Consumer Psychology, 15(3), 193-202.

Doel, M. (2007). Review: post-structuralist geography: a guide to relational space, Jonathan Murdoch. Annals of the Association of American Geographers, 97(4), 809-810.

Eckhardt, G., \& Bardhi, F. (2016). The relationship between access practices and economic systems. Journal of the Association of Consumer Research, 1(2), 210-225.

Eckhardt, G., \& Dobscha, S. (2019). The consumer experience of responsibilization: the case of Panera Cares. Journal of Business Ethics, 159, 651-663.

Ekström, K. (2019). Market orientation as the epicentre of art museums: museum shops, fashion exhibitions and private collections. In K. Ekström (Ed.), Museum marketization: cultural institutions in the neoliberal era. London, UK: Routledge.

Fisk, R., Dean, A., Alkire, L., Joubert, A., Previte, J., Robertson, N., \& Rosenbaum, M. (2018). Design for service inclusion: creative inclusive service systems by 2050 . Journal of Service Management, 29(5), 834-858.

Forman, R. T. (2014). Urban ecology: science of cities. Cambridge University Press.

Foster, J., \& McLelland, M. A. (2015). Retail atmospherics: the impact of a brand dictated theme. Journal of Retailing and Consumer Services, 22, 195-205.

Foucault, M. (1986[1967]). Of other places (trans: Miskowiec, J.). Diacritics, 16(1), 22-27.

Frosh, S. (2003). Psychosocial studies and psychology: is a critical approach emerging? Human Relations, 56(12), 1545-1567.

Frosh, S. (2010). Psychoanalysis outside the clinic: interventions in psychosocial studies. London, UK: Macmillan International Higher Education.
Frosh, S. (2014). The nature of the psychosocial: debates from studies in the psychosocial. Journal of Psycho-Social Studies, 8(1), $159-169$.

Frosh, S., \& Baraitser, L. (2008). Psychoanalysis and psychosocial studies. Psychoanalysis, Culture and Society, 13, 346-365.

Glasgow, T., Le, H., Geller, E., Fan, Y., \& Hankey, S. (2019). How transport modes, the built and natural environments, and activities influence mood: a GPS smartphone app study. Journal of Environmental Psychology, 66. Earlycite.

Giesler, M., \& Thompson, C. (2016). A tutorial in consumer research: process theorization in cultural consumer research. Journal of Consumer Research, 43(4), 497-508.

Giovanardi, M., \& Lucarelli, A. (2018). Sailing through marketing: A critical assessment of spatiality in marketing literature. Journal of Business Research, 82, 149-159.

Giovanardi, M., Kavaratzis, M., \& Lichrou, M. (2019). Critical perspectives on place marketing. In $\mathrm{M}$. Tadajewski, $\mathrm{M}$. Higgins, J. Denegri-Knott, \& R. Varman (Eds.), The Routledge Companion to Critical Marketing (pp. 115-134). Abingdon, UK: Routledge.

Goulding, C., \& Saren, M. (2009). Performing identity: an analysis of gender expressions at the Whitby Goth Festival. Consumption, Markets, \& Culture, 12(1), 27-46.

Grewal, D., \& Roggeveen, A. L. (2020). Understanding retail experiences and customer journey management. Journal of Retailing, 96(1), 3-8.

Grosz, E. (1994). Volatile bodies: toward a corporeal feminism. St. Leonards, Australia: Allan \& Unwin.

Guattari, F. (1989). Schizoanalytic cartographies (2013) (trans: Goffey, A.). Bloomsbury, London, UK.

Harvey, D. (1993). From space to place and back again: reflections on the condition of postmodernity. In J. Bird, B. Curtis, T. Putnam, J. Robertson, \& L. Tickner (Eds.), Mapping the futures: local cultures, global change (pp. 3-29). UK: Routledge. London.

Harvey, D. (2005). Space as a keyword. In Marx and Philosophy Conference, May, Institute of Education, London, UK, http:// www.inter-accions.org/sites/default/files/space-as-key-worddavid-harvey.pdf

Henshaw, V., Medway, D., Warnaby, G., \& Perkins, C. (2016). Marketing the 'city of smells.' Marketing Theory, 16(2), 153-170.

Hien, J., Evans, J., \& Jones, P. (2008). Mobile methodologies: theory, technology and practice. Geography Compass, 2(5), 1266-1285.

Hietanen, J., Andéhn, M., Iddon, T., Denny, I., \& Ehnhage, A. (2016). Consuming a machinic servicescape. In P. Moreau \& S. Puntoni (Eds.), NA - Advances in consumer research (pp. 304-308). Duluth, MN: Association for Consumer Research.

Hill, T. (2016). Mood management in the English premier league. In R. Canniford \& D. Bajde (Eds.), Assembling consumption: researching actors (pp. 155-171). Oxford: Networks and Markets, Routledge.

Hill, T., Canniford, R., \& Mol, J. (2014). Non-representational marketing theory. Marketing Theory, 14(4), 377-394.

Hoelscher, V., \& Chatzidakis, A. (2020). Ethical consumption communities across physical and digital spaces: an exploration of their complementary and synergistic affordances. Journal of Business Ethics, forthcoming

Hutton, M. (2019). The Care-less marketplace: exclusion as affective inequality. Consumption Markets \& Culture, 22(5-6), 528-544.

Johnstone, M., \& Todd, S. (2012). Servicescapes: the role that place plays in stay-at-home mothers' lives. Journal of Consumer Behaviour, 11(6), 443-453.

Kahneman, D. (2011). Thinking. Penguin, London, UK: Fast and Slow. 
Kates, S. (2002). The protean quality of subcultural consumption: an ethnographic account of gay consumers. Journal of Consumer Research, 29(3), 383-399.

Knoferle, K. M., Spangenberg, E. R., Herrmann, A., \& Landwehr, J. R. (2012). It is all in the mix: the interactive effect of music tempo and mode on in-store sales. Marketing Letters, 23(1), 325-337.

Kotler, P. (1973). Atmospherics as a marketing tool. Journal of Retailing, 49(4), 48-64.

Kozinets, R. (2002). Can consumers escape the market? Emancipatory illuminations from burning man. Journal of Consumer Research, 29(1), 20-38.

Kozinets, R. V., Sherry, J. F., Jr., Storm, D., Duhachek, A., Nuttavuthisit, K., \& DeBerry-Spence, B. (2004). Ludic agency and retail spectacle. Journal of Consumer Research, 31(3), 658-672.

Kuhn, T. (1962). The structure of scientific revolutions. Chicago, IL: University of Chicago Press.

Latour, B. (2005). Reassembling the social: an introduction to actornetwork-theory. Oxford: Oxford University Press.

Lefebvre, H. (1991). The production of space. Oxford, UK: Blackwell.

Lindstrom, M. (2009). Buyology: truth and lies about why we buy. New York, NY: Doubleday.

Low, S. M. (2016). Spatializing culture: the ethnography of space and place. Oxon, UK: Routledge.

Lucarelli, A., \& Giovanardi, M. (2019). Investigating relational ontologies in macromarketing: toward a relational approach and research agenda. Journal of Macromarketing, 39(1), 88-102.

MacInnis, D., Morwitz, V., Botti, S., Hoffman, D., Kozinets, R., Lehmann, D., et al. (2019). Creating boundary-breaking, marketing-relevant consumer research. Journal of Marketing, 84(2), 1-23.

Maclaran, P., \& Brown, S. (2005). The center cannot hold: consuming the utopian marketplace. Journal of Consumer Research, 32(2), 311-323.

McEachern, M., Warnaby, G., \& Cheetham, F. (2012). Producing and consuming public space: a 'rhythmanalysis' of the urban park. In Z. Gürhan-Canli, C. Otnes, \& R. Zhu (Eds.), Advances in consumer research (pp. 872-874). Duluth, MN: Association of Consumer Research.

Massey, D. (2005). For space. London, UK: SAGE.

Medway, D. (2015). Rethinking place branding and the 'other' senses. In M. Kavaratzis, G. Warnaby, \& G. Ashworth (Eds.), Rethinking Place Branding. Switzerland: Springer.

Medway, D., \& Warnaby, G. (2017). Multisensory place branding: a manifesto for research. In Campelo, A. (Ed.), Handbook on place branding and marketing (pp. 147-159).

Merriman, P., Jones, M., Olsson, G., Sheppard, E., Thrift, N., \& Tuan, Y. (2012). Space and spatiality in theory. Dialogues in Human Geography, 2(1), 3-22.

Miles, S. (2018). The emergence of contemporary consumer culture. In O. Kravets, P. Maclaran, S. Miles, \& A. Venkatesh (Eds.), The SAGE handbook of consumer culture. London, UK: SAGE.

Milliman, R. (1982). Using background music to affect the behaviour of supermarket shoppers. Journal of Marketing, 46(3), 86-91.

Milliman, R. (1986). The influence of background music on the behaviour of restaurant patrons. Journal of Consumer Research, 13(2), 286-289.

Moon, H., Yoon, H. J., \& Han, H. (2017). The effect of airport atmospherics on satisfaction and behavioral intentions: testing the moderating role of perceived safety. Journal of Travel \& Tourism Marketing, 34(6), 749-763.

Muñiz, A., \& O'Guinn, T. (2001). Brand community. Journal of Consumer Research, 27(4), 412-432.

Muñoz, C., \& Wood, N. (2009). A recipe for success: understanding regional perceptions of authenticity in themed restaurants.
International Journal of Culture, Tourism and Hospitality Research, 3(3), 269-280.

Muñoz, C., Wood, N., \& Solomon, M. (2006). Real or blarney? A cross-cultural investigation of the perceived authenticity of Irish pubs. Journal of Consumer Behaviour, 5(3), 222-234.

Murdoch, J. (2006). Post-structuralist geography: a guide to relational space. London, UK: Sage.

Panozzo, F. (2019). Sparking museums: the marketization of art institutions in the Heritage City. In K. Ekström (Ed.), Museum marketization: cultural institutions in the Neoliberal Era. London, UK: Routledge.

Parsons, L., Maclaran, P., \& Chatzidakis, A. (2016). Contemporary issues in marketing and consumer behaviour. Routledge, London, UK: Edited Volume.

Patterson, A., \& Brown, S. (2007). Inventing the pubs of Ireland: the importance of being postcolonial. Journal of Strategic Marketing, 15(1), 41-51.

Peñaloza, L. (1998). Just doing it: a visual ethnographic study of spectacular consumption behaviour at Nike Town. Consumption, Markets, and Culture, 2(4), 337-400.

Rashid, A., Barnes, L., \& Warnaby, G. (2016). Management perspectives on country of origin. Journal of Fashion Marketing and Management, 20(2), 230-244.

Regany, F., \& Emontspool, J. (2015). "They're taking us for fools" - when ethnic spectacles are perceived as dystopias. Consumer Culture Theory: Research in Consumer Behaviour, Volume 17 (pp. 295-309). Bingley, UK.

Pile, S. (1996). The body and the city: psychoanalysis, space and subjectivity. London and New York: Routledge.

Roelofsen, M., \& Minca, C. (2018). The superhost. Biopolitics, home and community in the Airbnb Dream-World of global hospitality. Geoforum, 91(May), 170-181.

Roffe, J. (2016). The concept of the assemblage and the case of markets. In R. Canniford \& D. Bajde (Eds.), Assembling consumption: researching actors (pp. 42-56). Oxford: Networks and Markets, Routledge.

Roggeveen, A. L., Grewal, D., \& Schweiger, E. B. (2020). The DAST framework for retail atmospherics: the impact of in-and outof-store retail journey touchpoints on the customer experience. Journal of Retailing, 96(1), 128-137.

Rosenbaum, M. (2005). The symbolic servicescape: your kind is welcomed here. Journal of Consumer Behaviour, 4(4), 257-267.

Rosenbaum, M. (2009). Restorative servicescapes: restoring directed attention in third places. Journal of Service Management, 20(2), 173-191.

Rosenbaum, M., \& Massiah, C. (2011). An expanded servicescape perspective. Journal of Service Management, 22(4), 471-490.

Rosenbaum, M., \& Walsh, G. (2012). Service nepotism in the marketplace. British Journal of Management, 23, 241-256.

Rosenbaum, M. S., Ward, J., Walker, B. A., \& Ostrom, A. L. (2007). A cup of coffee with a dash of love: an investigation of commercial social support and third-place attachment. Journal of Service Research, 10(1), 43-59.

Rosenbaum, M., Kelleher, C., Friman, M., Kristensson, P., \& Scherer, A. (2017). Re-placing place in marketing: a resource-exchange place perspective. Journal of Business Research, 79, 281-289.

Roux, D., Guillard, V., \& Blanchet, V. (2018). Of counter spaces of provisioning: reframing the sidewalk as a parasite heterotopia. Marketing Theory, 18(2), 218-233.

Saatcioglu, B., \& Ozzane, J. (2013). A critical spatial approach to marketplace exclusion and inclusion. Journal of Public Policy \& Marketing, 32(1), 32-37.

Sandberg, J. \& Alvesson, M. (2020). Meanings of theory: clarifying theory through typification. Journal of Management Studies. EarlyCite. 
Saren, M., Parsons, E., \& Goulding, C. (2019). Dimensions of marketplace exclusion: representations, resistances and responses. Consumption Markets \& Culture, 5-6, 475-485.

Seamon, D. (1993). Dwelling, seeing, and designing: toward a phenomenological ecology. Edited Volume: SUNY Press, Albany, NY.

Sherry, J. Jr. (2013). Reflections of a scape artist: discerning scapus in contemporary worlds. In D. Rinallo, L. Scott, \& P. Maclaran (Eds.), Consumption and Spirituality.

Sherry, J., Jr., Kozinets, R., Duhachek, A., DeBerry-Spence, B., Nuttavuthisit, K., \& Storm, D. (2004). Gendered behaviour in a male preserve: role playing at ESPN Zone Chicago. Journal of Consumer Psychology, 14(1\&2), 151-158.

Skandalis, A., Byrom, J., \& Banister, E. (2017). Spatial taste formation as a place marketing tool: the case of live music consumption. Journal of Place Management and Development, 10(5), 497-503.

Skandalis, A., Banister, E., \& Byrom, J. (2018). The spatial aspects of music taste: conceptualizing consumers' place-dependent identity investments. Marketing Theory, 18(2), 249-265.

Skandalis, A., Banister, E., \& Byrom, J. (2020). Musical taste and the creation of place-dependent capital: Manchester and the Indie Music Field. Sociology, 54(1), 124-141.

Soja, E. (1989). Postmodern geographies: the reassertion of space in critical social theory. New York: Verso.

Spangenberg, E. R., Grohmann, B., \& Sprott, D. E. (2005). It's beginning to smell (and sound) a lot like Christmas: the interactive effects of ambient scent and music in a retail setting. Journal of Business Research, 58(11), 1583-1589.

Spangenberg, E. R., Crowley, A. E., \& Henderson, P. W. (1996). Improving the store environment: do olfactory cues affect evaluations and behaviors? Journal of Marketing, 60(2), 67-80.

Spence, C., Puccinelli, N. M., Grewal, D., \& Roggeveen, A. L. (2014). Store atmospherics: A multisensory perspective. Psychology \& Marketing, 31(7), 472-488.

Steadman, C., Roberts, G., Medway, D., Millington, S., \& Platt, L. (2020). (Re)thinking place atmospheres in marketing theory (pp. 1-20). EarlyCite: Marketing Theory.

Thomas, T., Price, L., \& Schau, H. (2013). When differences unite: resource dependence in heterogeneous consumption communities. Journal of Consumer Research, 39(5), 1010-1033.

Thomas, T., Epp, A., \& Price, L. (2020). Journeying together: aligning retailer and service provider roles with collective consumer practices. Journal of Retailing, 96(1), 9-24.

Thompson, C., Arnould, E., \& Giesler, M. (2013). Discursivity, difference, and disruption: genealogical reflections on the consumer culture theory heteroglossia. Marketing Theory, 13(2), 149-174.

Thompson, C., \& Arsel, Z. (2004). The Starbucks brandscape and consumers' (anticorporate) experiences of glocalization. Journal of Consumer Research, 31(3), 631-642.
Thompson, C., \& Üstüner, T. (2015). Women skating on the edge: marketplace performances as ideological edgework. Journal of Consumer research, 42(2), 235-265.

Thrift, N. (2008). Non-representational theory: space. Affect, Routledge, Oxford: Politics.

Tifferet, S., \& Vilnai-Yavetz, I. (2017). Phytophilia and service atmospherics: the effect of indoor plants on consumers. Environment and Behavior, 49(7), 814-844.

Turley, L., \& Chebat, J. (2002). Linking retail strategy, atmospheric design and shopping behaviour. Journal of Marketing Management, 18(1-2), 125-144.

Turley, L., \& Milliman, R. (2000). Atmospheric effects on shopping behaviour: a review of the experimental evidence. Journal of Business Research, 49(2), 193-211.

Underhill, P. (2009). Why we buy: the science of shopping. New York, NY: Simon \& Schuster.

Vargo, S., \& Koskela-Huotari, K. (2020). Advancing conceptual-only articles in marketing. AMS Review, 10, 1-5.

Venkatraman, M., \& Nelson, T. (2008). From servicescape to consumptionscape: a photo-elicitation study of Starbucks in the New China. Journal of International Business Studies, 39(6), $1010-1026$

Venkatraman, M., \& Nelson, T. (2009). From servicescape to consumptionscape: a photo-elicitation study of starbucks in the New China. Journal of International Business Studies, 39, $1010-1026$.

Verhoef, P. C., Lemon, K. N., Parasuraman, A., Roggeveen, A., Tsiros, M., \& Schlesinger, L. A. (2009). Customer experience creation: determinants, dynamics and management strategies. Journal of Retailing, 85(1), 31-41.

Vicdan, H., \& Hong, S. (2018). Enrollment of space into the network of sustainability. Marketing Theory, 18(2), 169-187.

Visconti, L., Sherry, J., Borghini, S., \& Anderson, L. (2010). Street art, sweet art? Reclaiming the "public" in public place. Journal of Consumer Research, 37(3), 511-529.

Vukadin, A., Lemoine, J. F., \& Badot, O. (2019). Store artification and retail performance. Journal of Marketing Management, 35(7-8), 634-661.

Warnaby, G., \& Medway, D. (2013). What about the 'place' in place marketing? Marketing Theory, 13(3), 345-363.

Warnaby, G., \& Medway, D. (2017). Pretty vacant? implications of neglect and emptiness for urban aesthetics and place branding. In A. Campelo (Ed.), Handbook on place branding and marketing (pp. 219-235). Cheltenham, UK: Edward Elgar Publishing.

Woodward, K. (2015). Psychosocial studies - an introduction. Oxon, UK and New York, NY: Routledge.

Publisher's Note Springer Nature remains neutral with regard to jurisdictional claims in published maps and institutional affiliations. 